\title{
International Perspectives on CS Teacher Formation and Professional Development
}

\author{
Francesco Maiorana \\ Università di Catania \\ IISS G.B. Vaccarini \\ Italy \\ fmaioran@gmail.com \\ Chery Lucarelli \\ College of St. Scholastica \\ USA \\ clucarelli@css.edu
}

\author{
Miles Berry \\ University of Roehampton United \\ Kingdom \\ m.berry@roehampton.ac.uk \\ Margot Phillips \\ ACG Sunderland College \\ New Zealand \\ margot.phillipps@gmail.com \\ Andrea Benassi \\ INDIRE, Offices of Naples, Florence, \\ Turin, Italy \\ a.benassi@indire.it
}

\author{
Mark Nelson \\ Computer Science Teachers \\ Association \\ USA \\ m.nelson@csteachers.org \\ Shitanshu Mishra \\ Indian Institute of Technology \\ India \\ shitanshu@iitb.ac.in
}

\section{SUMMARY}

Drawing on Mishra and Koehler's 'TPACK' model [1], we recognize that great Computer Science (CS) teaching demands great pedagogy, great technology skills and great subject knowledge. The main challenge facing any jurisdiction in implementing a CS curriculum within schools is the shortage of new teachers being trained in CS1 and to meet the demand many countries have focused on professional development (PD) for existing teachers across a diverse range of subjects. Some initial PD efforts in CS were often brief, with little follow-on support, and supported through external grant funding. As the need for $\mathrm{CS}$ at the K-12 level continues to grow, approaches should be sustainable and scalable. This includes preparing teachers at all levels, pre k-12 and some funding initiatives have included preservice teacher support as part of this [2]. Inside the European Union (EU) the Scientix project [3] represents a focus European Commission (EC) funded projects and is a repository for PD with resources for pedagogy, technology and subject knowledge ${ }^{1}$. Besides this effort, spreading CS knowledge has been supported by volunteers led movements like CoderDojo ${ }^{2}$. The panelists will discuss the following main topics: 1) Preservice vs in-service, where do teachers come from? 2) Interdisciplinary ways of infusing CS. 3) Ways of replicatingacross countries CS teacher training initiatives aimed at sustaining and growing the number and quality of both inservice and pre-service teachers able to teach CS effectively. 4) Effective approaches to help teachers to build confidence in their ability to teach CS.

\footnotetext{
${ }^{1}$ www.scientix.eu/

${ }^{2}$ https://coderdojo.com/
}

Permission to make digital or hard copies of part or all of this work for personal or classroom use is granted without fee provided that copies are not made or distributed for profit or commercial advantage and that copies bear this notice and the full citation on the first page. Copyrights for third-party components of this work must be honored. For all other uses, contact the Owner/Author(s). Copyright is held by the owner/author(s).

ITiCSE'17, July 3-5, 2017, Bologna, Italy.

ACM. ISBN 978-1-4503-4704-4/17/07.

DOI: http://dx.doi.org/10.1145/3059009.3059067

\section{Panelist Position Statements}

\section{Miles Berry}

Faced with the challenge and opportunity of implementing a new national curriculum computing, with a significant emphasis on programming and other elements of computer science, the UK's Computing At School (CAS) group has emphasised the development of teachers' subject knowledge as a priority in continuing professional development (CPD). CPD through CAS has emphasised a geographically distributed peer-to-peer model. A network of nearly 450 'master teachers' has been established [4], supported by over 230 local hubs and ten universities as regional centres. A number of training programmes that could be used by these master teachers (and others) have been developed, and made freely available through financial support from industry and central government. Other initiatives have included Barefoot Computing, the BCS certificate in computer science teaching, Code Club Pro, PiCademy and a number of MOOCs. Despite this provision, many teachers report that it has been difficult to find the time to engage in meaningful professional development, due to the normal demands made on class teachers.

\section{Mark Nelson}

Approaches that enable teachers to integrate CS and computational thinking concepts and practices into their existing classes may be an effective approach to helping teachers build confidence in their ability to teach CS. In the US we estimate that there are more than 150 different professional development providers for CS. This can create a confusing environment for teachers new to the subject area. The Computer Science Teachers Association (CSTA) is working on an initiative called the Continuing Professional Development Pipeline. By working with PD providers, this project will support teacher professional development through micro-credentialing, developmental assessments, common communities, and customized professional development pathways. Via this model we aim to help teachers find the professional development best suited to their needs and interests. This project is supported by the Infosys Foundation USA. 


\section{Chery Lucarelli}

The College of Scholastica, through a unique partnership between a Computer Science faculty member and an Education faculty member, has been able to offer professional development in computer science since 2011. Efforts at The College of St. Scholastica, include offering an online graduate Certificate in CS Education to practicing teachers. The teacher preparation programs are being revised to infuse computational thinking across a number of courses and it will include an optional minor in computer science education for preservice teachers. Ultimately, all of our teachers will have a basic computational thinking competency and awareness and an opportunity to dive deeper into $\mathrm{CS}^{1}$.

\section{Margot Phillipps}

New Zealand is on the brink of introducing Computational Thinking into the compulsory national curriculum for years one to ten. Since 2011 there have been formal standards to assess elements of Computer Science in the Senior years of high school. These standards were introduced with a minimum of government supported professional development for teachers. For Computer Science, and to some extent Programming, this deficit has been met by CS4HS events and a website set up by Professor Tim Bell and post-graduate students at Canterbury University. Another program has been funded by a local IT company, Datacom, to train teachers in programming with support of a local teacher and volunteers from the company. The subject association, NZACDITT, has had a vibrant online group with teachers sharing resources and the burden of assessment moderation. Other universities have developed and plan further development of resources to aid the teaching of Programming. CodeAvengers have developed online learning resources for students. This approach has been ad hoc, dependent on the motivation and good will of many volunteers. It is hoped that the planned changes to the compulsory curriculum will be better planned and resourced centrally.

\section{Shitanshu Mishra}

The research focus of the interdisciplinary program in Educational Technology (IDP-ET) are two-pronged: 1) design based implementation research to refine the design of tertiary level, in-service teacher professional development (TPD) programs; 2) educational design research on developing pedagogies and technology-based learning environments for learning-teaching of pan-domain thinking skills. IDP-ET conducts various outreach programs which range from a single day workshop to full-length online teachers' training course. The longer outreach activities, utilize the design-based implementation research methodology to ensure scalability, sustainability of the efforts and feeds back to research by assisting in action research by participating teachers. The most recent outreach activity was a Teacher PD MOOC using IIT Bombay's Edx platform (IITBx). The MOOC was based on the design considerations of immersivity and pertinency to increase the learner perseverance in the course. For the second goal of thinking skills education, our primary research objective is to evolve a pedagogical framework to design effective learning environments for learning-teaching of thinking skills. Thinking skills are regarded as abilities and processes that human beings apply for sense-making, reasoning and problem-solving, and thinking skills in engineering and science include system design, computational thinking, troubleshooting, question-posing, hypotheticodeductive reasoning, etc. We envision the merging of the two approaches once we develop a community of teachers performing action research on the development of student thinking skills (Computational Thinking (CT) in the case of CS Education).

\section{Andrea Benassi}

A first reflection drawn by the fact that in England, Computer Science is embedded in the curriculum starting at the age of five. This choice is quite distant from the Italian way, where CS is not a discipline hitherto been considered but rather a "tool at the service" or a "transversal competencies" with respect to one or more disciplines. The idea of "computational thinking" as a fourth core competency (next to reading, writing, and numeracy) would seem to push a comprehensive application, but it poses at the same time a question: who are, in school, the teachers "owners" of this competency? If all teachers would be "responsible" for this competence, and no one would be in charge of it in an outstanding way, it is very likely that we would develop the same equity in the students. How could we go beyond? One could argue that the conceptual node lays in teacher training. If so, however, would it be enough to train teachers in diverse range of subjects to CS content and methods to get different results? What we argue, as a reflection from initiatives carried out in the Italian Digital School Plan, is that this is nor the main neither the only way. As well as math teacher is not only a teacher "trained to teach mathematics" but also and above all a bearer of a certain attitude, a certain way of approaching the real experience embodying passion and love for one type of organized mathematical knowledge and leads pupils along this path, the same has to be supported as for teaching computational thinking and computer science. We would like to engage and stimulate a deeper reflection about a specific teacher's profile capable to embody a true CT attitude, passion and love to involve students in a deep learning experience.

\section{${ }^{1}$ ACKNOWLEDGMENTS}

This material is based upon work supported by the National Science Foundation under Grant Nos. CNS-1240841, CNS1440947, and CNS-1547051 and by multiple Google research programs.

\section{REFERENCES}

[1] Mishra, P. and Koehler, M.J., 2006. Technological pedagogical content knowledge: A framework for teacher knowledge. Teachers college record, 108(6), p.10-17.

[2] National Science Foundation (NSF) (2016), Computer science for all (CS for All: RPP). Retrieved from https://www.nsf.gov/pubs/2017/nsf17525/nsf17525.htm.

[3] European Schoolnet (EUN) Scientix 2 results. How Scientix adds value to STEM education Authors: Róbert Hlynur Baldursson and Michael John Stone Contributors: Àgueda Gras-Velázquez, Marina Jiménez Iglesias, Radostina Karageorgieva, Valentina Garoia, Victor J. Pérez Rubio.

[4] Sue Sentance, Simon Humphreys, and Mark Dorling. 2014. The network of teaching excellence in computer science and master teachers. In Proceedings of the 9th Workshop in Primary and Secondary Computing Education (WiPSCE '14). ACM, New York, NY, USA, 80-88. DOI=http://dx.doi.org/10.1145/2670757.2670789. 